\title{
SPIRITUALITAS KRISTEN DI ERA POSTMODERN
}

Febriaman Lalaziduhu Harefa ${ }^{1}$

febriamanharefa@yahoo.com

Abstract: As the times progress from modern to post-modern, the principle of life also begins to change in accordance with the times, so does human spirituality, how do Christian attitudes judge the age and face this age? What kind of spirituality should be applied by believers? Considering the knowledge of Christian Spirituality in the Postmodern Era is very important, it is therefore necessary to provide an understanding of the insights of Christian spirituality, so that believers can wisely support this age.

Keywords: Spirituality, Christianity, Postmodern.

Abstraksi: Zaman semakin berkembang dari modern menjadi post-modern, prinsip hidup juga mulai berubah sesuai dengan zamannya, begitu juga dengan spiritualitas manusia, bagaimanakah sikap orang Kristen menilai zaman dan menghadapi zaman ini? Spiritualitas yang bagaimanakah yang harus diterapkan oleh orang percaya? Mengingat pengetahuan mengenai Spiritualitas Kristen di Era Postmodern sangat penting, oleh karena itu perlu memberikan pemhaman mengenai wawasan spiritualitas Kristen, agar orang percaya dapat bijaksana menghidupi zaman ini.

Kata Kunci: Spiritualitas, Kristen, Era Postmodern.

\section{PENDAHULUAN}

Istilah postmodernisme merupakan istilah yang sangat kontroversial. ${ }^{2}$

Dimana di satu pihak kerap dipergunakan dengan cara sinis, baik di bidang

1 Febriaman Lalaziduhu Harefa adalah Dosen Tetap bidang studi Theologia Historika di STT Ebenhaezer Tanjung Enim dan juga Dosen Tamu bidang studi Theologia Agama-Agama di STT Sriwijaya Palembang. Menyelesaikan Sarjana Theologia (S.Th) di STT Ebenhaezer Tanjung Enim tahun 2010 dan menyelesaikan Magister Theologia (M.Th) di Institut Injil Indonesia Batu tahun 2012.

2 Perlu dijelaskan bahwa ada beberapa kata yang hampir sama dengan kata postmodernisme. Pertama, postmodern yaitu suatu istilah yang menunjuk pada era atau zaman yang dibedakan dari era pra modern dan era modern. Kedua, postmodernitas yaitu suatu istilah yang memiliki hubungan dengan kondisi suatu masyarakat dalam hal tatanan hidup (khususnya pada tatanan sosial) dan keadaan manusia yang sedang bergelut dengan era atau zaman dimana dia tinggal dan berada yang bergerak dengan begitu cepat. Istilah ini juga menyangkut gaya hidup (style), kemajuan tekhnologi (di bidang informasi :televise, telpon selluler, dan internet. Serta terkait dengan transportasi : darat, laut dan udara), globalisasi, pluralisasi (kemajemukan) dan semua aspek yang berkaitan erat dengan aktivitas kehidupan semua manusia. Ketiga, postmodernis yaitu 
seni maupun filsafat, yaitu dianggap sebagai sekedar mode intelektual yang dangkal dan kosong. Akan tetapi dipihak lain istilah ini memikat minat masyarakat luas bahkan hingga dunia akademik. Hal ini memberikan gambaran bahwa saat ini manusia sedang menghadapi krisis perubahan sosiokultural fundamental. $^{3}$

Secara etimologi, istilah postmodernisme merupakan gabungan dari tiga kata berbeda yaitu kata post, modern dan isme. Kata post merupakan sebuah preposisi, dimana di dalam Kamus Latin-Indonesia, kata post memiliki dua arti. Pertama, berkaitan dengan tempat, dimana kata post berarti di belakang. Kedua, berkaitan dengan waktu dan urutan, kata post berarti kemudian, sesudah atau berikutnya. ${ }^{4}$ Kata modern berasal dari bahasa Latin yaitu modernus yang berarti sekarang. ${ }^{5}$ Kata ini lebih mengacu kepada keterangan waktu, dimana penekan dari kata modern adalah kekinian atau kemutahiran. Dengan demikian, modern sangat kontras dengan yang kuno, tua atau hal yang lama. ${ }^{6}$ Sementara akhiran (sufiks) isme berasal dari Bahasa Inggris mengandung beberapa pengertian seperti tindakan atau praktik, keadaan atau kondisi, prinsip, doktrin, teori dan sistem atau aliran. ${ }^{7}$ Jika kata isme ini menjadi sufiks pada kata postmodern maka artinya adalah praktik, keadaan atau kondisi, prinsip, doktrin, teori, sistem atau aliran dan karateristik dari masa yang melampauhi atau yang mengikuti masa modern. ${ }^{8}$ Ramly B. Lumintang menegaskan bahwa "postmodernisme dengan akhiran isme-nya menunjuk kepada pemikiran, paham (filosofi) atau aliran."9

\footnotetext{
kaum yang menganut paham postmodernisme. Band. Ramly B. Lumintang, Bahaya Postmodernisme \& Peranan Kredo Reformed, (Batu : Departemen Multimedia IPO, 2010), 36-17

${ }^{3}$ I Bambang Sugiharto, Postmodernisme : Tantangan Bagi Filsafat, (Yogyakarta : Penerbit Kanisius, 2008), 15

${ }^{4}$ K. Prent, Kamus Latin-Indonesia, (Yogyakarta : Kanisius, 1969), 658

5 C.L. Barnhart \& Jess Stein, The American College Dictionary, (New York : Random House and Toronto, 1964), 781

${ }^{6}$ Anton M. Moeliono, Kamus Besar Bahasa Indonesia, (Jakarta : Balai Pustaka, 1990), 589

${ }^{7}$ K. Prent, Kamus Latin-Indonesia, ..., 647

${ }^{8}$ Willy Gaut, Filsafat Postmodernisme : Jean Francois Lyotard, (Maumere : Penerbit Ledalero, 2010), 15

${ }^{9}$ Ramly B. Lumintang, Bahaya Postmodernisme \& Peranan Kredo Reformed, ..., 38
} 
Dapatlah disimpulkan bahwa postmodernisme adalah suatu paham atau pokok pemikiran yang meruntuhkan prinsip-prinsip tatanan nilai dan diskursus akademis modernisme. Seperti halnya dituliskan oleh I Bambang Sugiharto sebagai berikut. Pertama menunjuk kepada kritik-kritik filosofis atas gambaran dunia (world view), epistemologi dan ideologi-ideologi modern. Yang kedua, menunjuk pada situasi dan tata social produk teknologi informasi, globalisasi, fragmentasi gaya hidup, konsumerisme yang berlebihan, deregulasi pasar uang dan sarana publik. ${ }^{10}$ David S. Dockery di dalam buku The Challenge of Postmodernism an Evangelical Engagement menuliskan sebagai berikut :

Postmodernism is a new set of asusumption about reality, which goes far beyond mere relativism. It impact our literature, our dress, our art, our architectur, our music, our sense right or wrong, our self identity and our theology. ${ }^{11}$

Definisi postmodernisme lebih spesifik dituliskan oleh Ramly B Lumintang, yaitu :

Postmodernisme dengan filosofinya, "pemikiran" dan semangat ajaran yang terkandung di dalamnya, telah meruntuhkan modernisme. Di samping itu memunculkan sesuatu yang "baru" seperti penekanan pada humanism (anthroposentris) yang ekstrem (sangat berlebihan) terutama dalam kebebasannya, mengokohkan relativisme absolut (semua adalah relatif) sebagai patokan segala sesuatu, berdasarkan prespektif (paradigma seseorang) untuk menjadi ukuran dalam mencari kebenaran, gaya hidup yang bebas berekspresi (mengikuti kata hati) demi mencapai kesenangan, pola hidup : konsumeristik, sektarianistik, komersialistik, hedonistik, dan pragmatistik, yang semuanya telah merambah serta mempengaruhi hamper ke seluruh aspek kehidupan manusia (baik bidang sosial, politik, ekonomi, kebudayan, seni, filsafat, etika dan termasuk theology. ${ }^{12}$ 1996), 24

${ }^{10}$ I. Bambang Sugiharto, Postmodernisme : Tantangan Bagi Filsafat, (Yogyakarta : Kanisius,

11 David S. Dockery, The Challenge of Postmodernism an Evangelical Engagement, (Grand Rapids : Baker Books, 1995), 14

${ }^{12}$ Ramly B. Lumintang, Bahaya Postmodernisme \& Peranan Kredo Reformed, ..., 38 
Penertian di atas, memberikan deskripsi logis bahwa eksistensi postmodernisme adalah suatu tindakan radikal yang mengoreksi pola pikir dan sistem kerja modernisme dengan membangun rumusan baru yang berbeda dengan modernisme. Dalam konteks iman Kristen, filsafat postmdernisme berupaya merobek tatanan nilai-nilai iman Kristiani yang absolute, mutlak dan final. Mencoba meruntuhkan (decontruksi) penyatan Alkitab sebagai firman Allah dan berusaha membangun (reconstruksi) penyataan iman yang baru, dimana makna dan nilai-nilai hakikinya berbeda dengan penyataan Alkitab firman Allah. Tidak ada kebenaran final dan absolute, yang ada kebenaran individu (manusia) sebagai pencipta makna. Maka pada hakikatnya, kebenaran dalam filsafat postmodern adalah nihil dan relatif. Hal inilah yang membut manusia, berdiri atas pengertiannya sendiri. Allah dan Alkitab hanyalah pelengkap kebutuhan semata. Hubungan dengan Sang Pencipta hanyalah "pemuas psikologi semata" dan Allah hanyalah kebutuhan sekunder dalam kehidupan pribadi manusia. Maka tidak ada ukuran terhadap karakter yang baik dan bermoral, karena semua sifat dan karakter manusia yang selama ini dijaga sudah kehilangan "posisinya" dan sama sekali tidak relevan dengan kehidupan masa kini. Maka muncullah sifat egosentris, konsumerisme, materialism dll. Filsafat postmodernisme telah menciptakan sebuah filosofi bahwa "aku adalah kebenaranku sendiri dan aku hidup untuk diriku sendiri”. Bagaimana Kekristenan harus hidup dalam zaman seperti ini? Siapakah yang harus diteladani?. Tulisan ini dibuat, karena keprihatinan penulis terhadap zaman yang tidak ada tujuan dan haluan hidup. Penulis ingin memproklamirkan kepada para pembaca bahwa dalam era postmodern, kita harus hidup dalam spiritualitas iman yang sejati. Sehingga pada hari Allah memanggil untuk menghadap Allah Tritunggal, kita kedapatan setia dihadapan-Nya

\section{DESKRIPSI SPIRITUALITAS KRISTIANI}


Alister E McGrath menuliskan dalam bukunya Christian Spirituality bahwa spiritualitas berasal dari kata ruach yang berarti roh, nafas atau angin. Artinya, Roh Kudus secara aktif memberikan hidup dan dorongan kepada orang percaya untuk bertindak sesuai firman Allah. Oleh sebab itu spriritualitas dalam prespektif kekristenansangat erat hubungannya dengan nilai-nilai iman, motifasi hidup, daya tahan, ketekunan serta semangat dalam menjalani hidup sesuai dengan apa yang dikehendaki Allah. ${ }^{13}$ Sedangkan, Andrew Brake menuliskan definisi pembentukan rohani (Spiritualitas Formations) yaitu seseorang yang menjadi semakin serupa dengan Kristus (1 Yohanes 3:2-3), seseorang yang mengalami kehidupan yang serupa dengan Kristus, seseorang yang sedang bertumbuh dalam kehidupan kerohaniaannya, dan seseorang yang hidup sesuai dengan harapan Yesus Kristus. ${ }^{14}$ Atas dasar inilah Christian Weiss memberikan sebuah kesimpulan bahwa :

Pada dasarnya kehidupan Kristen adalah persekutuan dengan Allah. Hal menjadi orang Kristen pertama-tama berarti berada dalam persekutuan yang betul dengan Allah. Bukan memperbaiki atau mengubah kehidupan yang lama, melainkan menerima dan masuk dalam kehidupan yang baru, dijadikan "kejadian baru" pindah dari mati kepada hidup, menjadi rumah Roh Kudus, ia ditebus, dibeli dengan harga tunai, menjadi anakanak Allah, orang saleh, hamba Allah, sebagai utusan Kristus dan orang yang bekerja sama dengan Allah. Semua ini dikerjakan di dalam dia oleh pekerjaan anugerah dan kuasa ilahi, bukan karena jasa atau usaha pribadi. ${ }^{15}$

Pembentukan rohani (Spiritualitas Formations) bukanlah hanya berbicara tentang kehidupan dalam doa, aktifitas dalam berpuasa, melayani Allah, bekerja sesuai dengan nilai-nilai iman Kristiani ataupun keaktifan dalam kegiatan-kegiatan keagamaan. Hal-hal di atas, hanyalah salah satu bagian dari pembentukan rohani (Spiritualitas Formations). Hal yang paling mendasar dan fundamental dalam pembentukan rohani (Spiritualitas

\footnotetext{
${ }_{13}$ Alister E McGrath, Christian Spirituality, (UK : Blackweell Publishing, 2003), 2

${ }^{14}$ Andrew Brake, Spiritual Formations, (Bandung : Kalam Hidup, 2013), 7

${ }^{15}$ Christian Weiss, Pedoman Mencari Kehendak Allah,..., 37
} 
Formations) adalah pemahaman, dan penerimaan akan karya dan pekerjaan Tuhan Yesus Kristus dalam menguduskan orang percaya agar memiliki persekutuan dengan Dia. Rasul Paulus memberikan penegasan akan hal ini dalam 1 Korintus 1:2 yang berbunyi "kepada jemaat Allah di Korintus, yaitu mereka yang dikuduskan dalam Kristus Yesus dan yang dipanggil menjadi orang-orang kudus, dengan semua orang disegala tempat, yang berseru kepada nama Tuhan kita Yesus Kristus, yaitu Tuhan mereka dan Tuhan kita". Paul Ellingworth \& Howard Hatton dalam buku A Translator's Handbook on Paul's First Letter to the Corinthians memberikan pengertian tentang kata "dikuduskan" pada teks 1 Korintus 1:2. Yaitu kata "dikuduskan dan orangorang kudus" mengungkapkan bahwa orang percaya adalah milik Allah, sehingga dipisahkan sesara khusus untuk melayani-Nya, sesuai rencana-Nya yang agung. Kudus dalam teks ini bukan sekedar tidak berbuat dosa, melainkan lebih merujuk kepada hubungan orang percaya kepada Allah karena orang percaya adalah milik Allah. ${ }^{16}$

Teks di atas memberikan sebuah pengertian bahwa Tuhan Yesus Kristus adalah aktif dalam menanamkan nilai-nilai iman dan keselamatan dalam kehidupan manusia. Artinya, tidak ada sedikitpun andil manusia dalam hal keselamatan manusia. Allah dalam kedaulatan-Nya yang memberikan secara cuma-cuma kepada orang yang berkenan kepada-Nya. Dalam Efesus 2:8-10 berbunyi "Sebab karena kasih karunia kamu diselamatkan oleh iman, itu bukan hasil usahamu, tetapi pemberian Allah, itu bukan hasil pekerjaanmu: jangan ada orang yang memegahkan diri. Karena kita ini buatan Allah, diciptakan dalam Kristus Yesus untuk melakukan pekerjaan baik, yang dipersiapkan Allah sebelumnya. Ia mau, supaya kita hidup di dalamnya.Namundemikian, dalam proses hidup sebagai musafir di dunia ini, orang percaya haruslah sungguh-sungguh menjaga dan memelihara anugerah

\footnotetext{
${ }^{16}$ Paul Ellingworth \& Howard Hatton, A Translator's Handbook on Paul's First Letter to the Corinthians. Telah diterjemahkan ke dalam bahasan Indonesia Paul Ellingworth \& Howard Hatton, Surat Paulus Yang Pertama Kepada Jemaat Di Korintus, (Jakarta : Lembaga Alkitab Indonesia, 2010), 7
} 
keselamatan, serta hidup dalam ketekunan iman di dalam Tuhan Yesus Kristus. Itulah sebabnya Rasul Paulus juga menegaskan di dalam Filipi 2:1213 "Hai saudara-saudaraku yang kekasih, kamu senantiasa taat; karena itu tetaplah kerjakan keselamatanmu dengan takut dan gentar, bukan saja seperti waktu aku masih hadir, tetapi terlebih pula sekarang waktu aku tidak hadir, karena Allahlah yang mengerjakan di dalam kamu baik kemauan maupun pekerjaan menurut kerelaan-Nya". Rasul Paulus ingin menegaskan bahwa tanggung jawab orang percaya adalah mengerjakan keselamatan dengan rasa takut dan gentar. Namun dengan keyakinan bahwa Allah yang akan melakukan pekerjaan itu dengan memberikan kemampuan khusus kepada umat-Nya. Oleh sebab itu, orang percaya secara terus menerus menjaga komunikasi kepada Allah dan berserah penuh kepada-Nya dalam kondisi apapun dalam kehidupannya.

Berdasarkan pemaparan teks di atas, maka dapatlah dipahami bahwa pembentukan rohani (Spiritualitas Formations) adalah karya Tuhan Yesus Kristus di dalam pimpinan Roh Kudus dalam kehidupan orang percaya. Pembentukan rohani (Spiritualitas Formations) akan membawa setiap orang untuk mematuhi kehendak Roh Kudus. Dengan demikian, orang percaya akan bersatu dengan Allah dan semua orang percaya dengan kasih. Oleh sebab itu, semestinya dalam menghadapi tantangan zaman sekaligus tantangan dalam bertheology di abad XXI dewasa ini, haruslah meneladani Tuhan Yesus Kristus dalam hal keteladan hidup dan spiritual. Hal ini tidak dapat diragukan lagi sebab Tuhan Yesus Kristus adalah tokoh yang sangat ideal berbicara tentang keteladan spiritual. Walaupun dalam laporan Injil Sinoptik, tidak ditemukan sama sekali berita yang memuat bahwa Ia aktif dalam memakai atribut-atribut keagamaan (khususya Yudaisme) dalam melaksanakan aktifitasnya sehari-hari. Ia tidak memakai jubah kebesaran agamawi dan menunjukkan diri sebagai manusia yang paling agamawi. Seperti berdoa dipersimpangan jalan agar mendapatkan penilaian dari masyarakat luas 
bahwa Ia adalah manusia yang sangat rohani. Semangat pelayanan-Nya di Sinagoge dalam hal menyampaikan kebenaran, bukanlah dalam rangka "mencari muka" ataupun "menyukakan hati pendengar", melainkan proklamasi tentang nilai-nilai kebenaran, kasih dan keadilan Allah bagi umat manusia. Tuhan Yesus Kristus melakukan segala sesuatu dengan penuh ketulusan, didorong oleh belas kasihan dan dilakukan secara spontan yaitu dilakukan dimana dan kapan pun, tanpa dibatasi oleh hal apapun (Markus 1:21 \& 3:1). Ia dalam kedaulatan-Nya menyatakan ketegasan-Nya dalam hal dosa, dan dengan semangat menyampaikan kebenaran Allah. Les Carter menuliskan bahwa nilai-nilai spiritualitas Tuhan Yesus, nampak dalam kepeduliaan-Nya kepada umat manusia, pengorbanan-Nya yang tanpa batas, dan kepedulian-Nya dalam menjunjung tinggi nilai-nilai kemanusian. ${ }^{17}$ Artinya adalah kehidupan spriritualitas Tuhan Yesus Kristus bukanlah sebatas simbol atau teori keagamaan (theory religius) semata-mata, tetapi dibuktikan secara aktif dalam tindakan yang nyata. Dimana pada waktu itu yaitu kehidupan spiritual zaman Tuhan Yesus Kristus, nilai-nilai spiritual yang murni sangat jarang ditemukan di dalam kehidupan pemimpinpemimpin agama Yahudi. ${ }^{18}$

Dasar pelayanan Tuhan Yesus Kristus di dunia ini adalah kasih (Yohanes 3:16; 1 Yohanes 4). Dengan bertumpu kepada kasih-Nya, Tuhan Yesus Kristus mau melayani bukan untuk dilayani (Yohanes 13:1-20 ; Markus 10:45) dan meletakkan dasar penginjilan untuk mengasihi jiwa-jiwa yang tersesat (Yohanes 13:34-35). Dalam hal ini, Yakob Tomatala juga

\footnotetext{
${ }^{17}$ Les Carter, Reflecting the Character of Christ, (Nasville : Thomas Nelson Publishers, 1995), 4

${ }^{18}$ Dalam Matius 9:9-13 "Setelah Yesus pergi dari situ, Ia melihat seorang yang bernama Matius duduk di rumah cukai, lalu Ia berkata kepadanya: Ikutlah Aku. Maka berdirilah Matius lalu mengikut Dia. Kemudian ketika Yesus makan di rumah Matius, datanglah banyak pemungut cukai dan orang berdosa dan makan bersama-sama dengan Dia dan murid-murid-Nya. Pada waktu orang Farisi melihat hal itu, berkatalah mereka kepada murid-murid Yesus: Mengapa gurumu makan bersama-sama dengan pemungut cukai dan orang berdosa? Yesus mendengarnya dan berkata: Bukan orang sehat yang memerlukan tabib, tetapi orang sakit. Jadi pergilah dan pelajarilah arti firman ini: Yang Kukehendaki ialah belas kasihan dan bukan persembahan, karena Aku datang bukan untuk memanggil orang benar, melainkan orang berdosa". Markus 10:45" Karena Anak Manusia juga datang bukan untuk dilayani, melainkan untuk melayani dan untuk memberikan nyawa-Nya menjadi tebusan bagi banyak orang".
} 
menuliskan bahwa praktik pelayanan Yesus adalah pelayanan dalam kasih. Hal ini dibuktikan dengan sikap dan gaya pelayanan Tuhan Yesus Kristus :

Pertama, Yesus memenuhi tugas mesianik, apostolic dan kerajaan. Orang buta dapat melihat, yang lumpuh dapat berjalan, yang kusta menjadi tahir, yang tuli dapat mendengar, yang mati dibangkitkan, yang miskin mendengar berita kabar baik (Matius 11:2-5 ; Lukas 4:18-19 ; 7:19-22). Kedua, Yesus melaksanakan tugas penginjilan dalam "three fold ministry" pelayanan tiga ganda (Matius 9:35) secara utuh dan sempurna, ke manapun Ia pergi, yaitu : (a). Mengajar, yaitu menjelaskan tentang firman Tuhan guna melenyapkan ketidaktahuan serta mengubah konsepsi kepada pengetahuan dan pengenalan akan Allah secara benar. (b). Berkhotbah, atau memberitakan Injil Kerajaan Allah, yang menyelamatkan serta membebaskan dari dosa. (c). Menyembuhkan, yang menggambarkan bahwa di dalam pembebasan Allah melalui Tuhan Yesus Kristus ada pembebasan fisik dari akibat dosa, ini menyangkut pembebasan total dari Allah. ${ }^{19}$

Demikian halnya gereja dan orang percaya, yang diutus oleh Allah sebagai saksi-Nya di dunia ini. Tentu haruslah memiliki spiritualitas yang benar-benar nyata seperti Yesus Kristus. Orang percaya di era postmodern, bukan hanya menunjukkan status sebagai seorang yang memiliki agama. Melainkan mendemonstrasikan nilai-nilai kebenaran itu bagi dunia ini, baik itu sifat ilahi yang tertanam di dalam hati, karakter yang telah diubahkan, keteladan hidup maupun kehidupan doa dan persekutuan dengan Allah. Orang percaya haruslah menjaga kekudusan hidup di tengah kemajuan zaman yang terus menerus berubah. Tentu hal ini haruslah secara konsisten dan terus-menerus dilakukan, sebab merupakan aktifitas orang percaya dalam rangka penyembahan kepada Allah yang Kudus. ${ }^{20}$ Rasul Petrus menegaskan dalam suratnya 1 Petrus 1:15-16 bahwa "tetapi hendaklah kamu menjadi

\footnotetext{
${ }^{19}$ Yakob Tomatala, Penginjilan Masa Kini,..., 42

${ }^{20}$ Beberapa catatan akan dibahas di sini bahwa kekudusan merupakan standart Allah dalam memanggil dan mempercayakan pelayanan kepada seseorang. Berikut akan dipaparkan beberapa contoh tentang tokoh-tokoh Alkitab yang berhubungan dengan kekudusan ini. Pertama, Allah memanggil Musa.
} 
kudus di dalam seluruh hidupmu sama seperti Dia yang kudus, yang telah memanggil kamu, sebab ada tertulis: Kuduslah kamu, sebab Aku kudus".

Oleh sebab itu,J.L Packer dalam bukunya God's Plans For You menuliskan empat prinsip hidup yang dimiliki oleh seorang yang sudah dikuduskan oleh Yesus Kristus. Pertama, kehidupan merupakan kewajiban terhadap Allah yaitu memuliakan Dia melalui ketaatan yang timbul dari rasa syukur atas anugerah-Nya. Kedua, kehidupan mengasihi sesama. Yaitu mengasihi mereka seperti mengasihani diri sendiri. Kasih mengusahakan kebaikan dan kemajuan dalam segala hal. Kasih lebih dari pada soal pikiran dan kehendak, lebih merupakan komitmen jangka panjang dari pada intensitas sesaat. Kewajiban mengasihi sesama sama seperti kewajiban mengasihi Allah dan hal ini sangat memerlukan disiplin hidup. Ketiga, kehidupan yang merdeka (Galatia 5:1). Bebas dari keharusan mengusahakan keselamatan, bebas menggunakan dan menikmati segala hal ciptaan (1Timotius 4:4-5; 6:17) dan bebas dalam pengertian suatu kepenuhan dan kepuasan untuk bekerja bagi Allah, yaitu melayani Allah dengan kebebasan yang sempurna. Keempat, kehidupan yang diselamatkan adalah kehidupan dalam pengharapan kepada Allah yaitu untuk menerima firman dan pemberitaannya. $^{21}$

\section{APA SAJA NILAI-NILAI SPIRITUALITAS KRISTIANI}

Secara spesifik, di bawah ini akan dipaparkan nilai-nilai spiritualitas Kristiani seperti tercatat di dalam Alkitab. Nilai-nilai spiritualitas Kristiani ini akan menjadi model bagi orang percaya dalam menghadapi arus zaman di era postmodern.Pertama, hidup baru di dalam tuhan Yesus Kristus (Efesus 4:1718). Hidup baru adalah kunci dasar melihat kerajaan surga. Dalam hal ini Rasul Paulus di dalam Efesus 4:17-18 menyatakan bahwa "Sebab itu kukatakan dan kutegaskan ini kepadamu di dalam Tuhan: Jangan hidup lagi

\footnotetext{
${ }^{21}$ J.L Packer, God's Plans For You, (Surabaya : Momentum, 2004), 91-92
} 
sama seperti orang-orang yang tidak mengenal Allah dengan pikirannya yang sia-sia dan pengertiannya yang gelap, jauh dari hidup persekutuan dengan Allah, karena kebodohan yang ada di dalam mereka dan karena kedegilan hati mereka. Perasaan mereka telah tumpul, sehingga mereka menyerahkan diri kepada hawa nafsu dan mengerjakan dengan serakah segala macam kecemaran". Penekanan dari teks itu adalah kerinduan hati Tuhan Yesus agar umat-Nya mengenakan manusia baru atau cara hidup yang baru dan masuk dalam hidup yang baru yaitu persekutuan di dalam Yesus Kristus.Dalam hal ini, R. V. G. Tasker menuliskan bahwa "But this reconcilition is not limited to men. It applies to the whole other of created being. It is significant that Paul does not here say 'all men', which would be contrary to this normal teaching, but 'all things'. The phrase is indefinite and suggests the completeness of the plan of God. Not only is sinful man reconciled, but the created order which has been made subject to vanity because of sin". ${ }^{22}$ Hal yang sama dituliskan juga oleh F. F. Bruce"Paul's statemen that christ's reconciling work, in accordance with the divine purpose, is to embrace in its scope 'all things...whether thing's upon the earth, or things in the heawens,' has been taken to mean that he looked for the ultimate reconciliation to God not only of all men but of hostile spiritual powers as well". ${ }^{23}$

Kedua, hidup yang dipimpin oleh Roh Kudus (Galatia 5:16).Dalam teks Galatia 5:16 ditegaskan bahwa orang yang telah menerima Yesus Kristus sebagai Juruselamat, hidupnya akan dipimpin oleh Roh Kudus. Dalam terjemahan Alkitab New International Version dituliskan "live by the Spirit (hiduplah oleh Roh), sedangkan dalam King James Version dituliskan "Walk in the Spirit (berjalan dalam Roh). Ayat ini ditulis dalam bentuk perintah dan

\footnotetext{
${ }^{22}$ R. V. G. Tasker (ed), The Epistles Of Paul to The Colossians \& Philemon, (Grand Rapids, Michigan: Wm. B. Eedmans publishing Company, 1982), 46-47

${ }^{23}$ E. K. Simpson \& F. F. Bruce (ed), The New International Commentary On The New Testament : The Epistles to The Ephesians and Colossians, (Grand Rapids, Michigan: Wm. B. Eerdmans Publishing Company, 1979), 209
} 
sifatnya sangat amat penting sehingga senantiasa dan secara terus menerus harus dilakukan dalam kehidupan orang percaya. ${ }^{24}$ William Hendriksen menuliskan "let your conduct be governed by the Spirit, that is, by God's gift imparted to you $(3: 2,5)$. If you follow his direction and promptings you will not be dominated by your human nature regarded as the seat and vehicle of sinful desire (as in 5:13), but instead will conquer it. It takes the tender leaves of early springtime to rid the oak tree of the remnants of last autumn's withered foliage". ${ }^{25}$ Kehidupan yang dipimpin Roh Kudus bukan berarti menikmati kebebasan, keberanian, dan kemenangan yang diberikan-Nya. Akan tetapi, orang percaya akan menjadi tawanan Roh Kudus dan bersedia menerima batasan-batasan yang ditetapkan oleh Allah Tritunggal. ${ }^{26}$ Dipimpin oleh Roh Kudus juga dapat dipahami sebagai pengakuan akan eksistensi Roh Kudus itu sendiri yang akan hadir serta diam dalam hidup orang percaya, mempercayakan diri kepada kuasa Allah dan mengharapkan pertolongan-Nya dalam segala kesulitan hidup, dan mengindahkan Dia sebagai pribadi yang selalu sedia menolong hidup orang percaya. Seseorang yang mau dipimpin oleh Roh, maka harus sedia meminta bimbingan dari Allah Tritunggal melalui Alkitab firman Allah. Sehingga, orang percaya sejalan dengan keinginan Roh Kudus. ${ }^{27}$

Ketiga, hidup yang mencerminkan buah Roh Kudus. Galatia 5:22-23 menyatakan sebuah kebenaran bahwa "buah Roh ialah kasih, sukacita, damai sejahtera, kesabaran, kemurahan, kebaikan, kesetiaan, kelemahlembutan, penguasaan diri. Tidak ada hukum yang menentang halhal itu". Dalam konteks ini istilah buah Roh Kudus adalah istilah Alkitab yang merangkum sembilan sifat nyata dari hidup Kristen yang sejati menurut

\footnotetext{
${ }^{24}$ Hasan Susanto, Perjanjian Baru Interlinier Yunani Indonesia \& Korkondansi Perjanjian Baru (PBIK) Jilid I, (Jakarta: Lembaga Alkitab Indonesia, 2010), 1020

${ }^{25}$ William Hendriksen, New Testament Commentary Galatians and Ephesians, (Michigan: Baker Book House, 1990), 214

${ }^{26}$ Stanley M. Horton, Oknum Roh Kudus, (Malang: Gandm Mas, 19

${ }^{27}$ A.B. Simpson, Mengikuti Pimpinan Roh, (Bandung: Kalam Kudus, tt), 12-14
} 
rasul Paulus. Di seluruh Alkitab, orang saleh diibaratkan seperti pohon dan pasal ini akan dijelaskan buah macam apa yang dihasilkan oleh "pohon yang baik" yaitu orang saleh atau orang benar.

Kata kasih dalam bahasa Yunaninya adalah agape. Kasih ini adalah kasih Allah (1 Yohahnes 4:16) dan dihasilkan di dalam hati orang percaya oleh Roh Kudus (Roma 5:5, Galatia 5:22). Kasih ini terdiri dari pengorbanan diri untuk keuntungan seseorang yang dicintai (Yohahes 3:16). ${ }^{28}$ Warren W. Wiersbe menuliskan bahwa agape adalah kasih ilahi. Kasih ilahi ini adalah karunia Allah pada orang percaya (Roma 5:5). Orang percaya harus memeliharanya dan berdoa kiranya kasih ini semakin melimpah-limpah (Filipi 1:9). ${ }^{29}$ William Barclay, agape adalah istilah Kristen yang berarti kebajikan yang dapat dibawa. Rasul Paulus di dalam 1 Korintus 13:1-3 menuliskan "Sekalipun aku dapat berkata-kata dengan semua bahasa manusia dan bahasa malaikat, tetapi jika aku tidak mempunyai kasih, aku sama dengan gong yang berkumandang dan canang yang gemerincing. Sekalipun aku mempunyai karunia untuk bernubuat dan aku mengetahui segala rahasia dan memiliki seluruh pengetahuan; dan sekalipun aku memiliki iman yang sempurna untuk memindahkan gunung, tetapi jika aku tidak mempunyai kasih, aku sama sekali tidak berguna. Dan sekalipun aku membagi-bagikan segala sesuatu yang ada padaku, bahkan menyerahkan tubuhku untuk dibakar, tetapi jika aku tidak mempunyai kasih, sedikitpun tidak ada faedahnya bagiku". Apapun yang diperbuat orang lain atas diri orang percaya, entah itu caci maki, sakit hati, ataupun penghinaan.Orang percaya akan tetap berbuat hal-hal yang terbaik bagi kemuliaan-Nya. Jadi, agape adalah segala sesuatu yang tidak hanya menyangkut, perasaan tetapi juga kemauan, tidak hanya mengena pada hati, tetapi juga pada pikiran.

\footnotetext{
${ }^{28}$ Kenneth S. Wuest, Wuest's Word Studies From The Greek New Testament For English Reader Volume One, (Grand Rapids, Michigan: Wm. B. Eerdmans, 1989), 159

${ }^{29}$ Warren W. Wiersbe, Be Free, An Expositions Study Of Galatians, (Wheaton, Illionis: Victor Books, 1981), 134
} 
Agape adalah upaya yang sengaja dilakukan oleh orang percaya, tanpa ada maksud jahat baik untuk diri sendiri maupun untuk orang lain. ${ }^{30}$

Sukacita (khara) berasal dari kata kerja khairo, bersukacita, bersenangsenang, dan digunakan sebagai salam saat bertemu. Sukacita memiliki sebuah aspek spiritual, seperti sukacita yang dikerjakan Roh Kudus (1Tesalonika 1:6). ${ }^{31}$ Menurut Wiersbe, sukacita adalah damai sejahtera dan kecukupan di dalam hati yang tidak dipengaruhi oleh keadaan luar. ${ }^{32}$ Sukacita menjadi penuh pada saat kerohanian yang hilang ditemukan kembali. ${ }^{33}$ Sukacita juga dapat dipahami sebagai kebaikan yang teritnggi dalam kehidupan Kristen yang berhubungan dengan kesenangan di dalam dunia yang sekuler ini. Kelihatannya keduanya memiliki arti yang sama, tetapi kesenangan tergantung kepada situasi ,sementara sukacita tidak. Sukacita adalah kegembiraan yang mendalam timbul dari hubungan pribadi dengan Allah (Filipi 4:4), yang mencakup hal orang percaya memenuhi kehendakNya. ${ }^{34}$ Sukacita Kristen adalah hasil dari sebuah teologi yang mendalam bahwa Allah mengendalikan segala sesuatu untuk kebaikan dan kemuliaanNya sendiri dan juga demi kebaikan oang-orang yang mengasihi Dia. Tuhan adalah sumber sukacita yang tak habis-habisnya. Kata Yunani Khara memiliki tiga makna utam dalam PB. Pertama, kegembiraan yang meluapluap (Lukas 15:7). Kedua, kegembiraan yang mendalam yang timbul dari hubungan pribadi dengan Allah (Filipi 4:4). Ketiga, secara metonimi, kesukaan, buah-buah, atau kasih dari sukacita.

Menurut Kenneth S. Wuest, damai di sini adalah damai yang dari Allah di dalam hati orang percaya dan dapat didefinisikan ketenangan pikiran yang

\footnotetext{
${ }^{30}$ William Barclay, Pemahaman Alkitab Setiap Hari Kitab Galatia dan Efesus, (Jakarta: BPK Gunung Mulia, 2000), 79-80

${ }^{31}$ Kenneth S. Wuest, Wuest's Word Studies From The Greek New Testament..., 160

${ }^{32}$ Warren W. Wiersbe, Be Free, An Expositions..., 135

${ }^{33}$ James Montgomery Boice, The Expositors Bble Commentary, (Grand Rapids, Michigan: Zondervan Publishing House, 1995), 499

${ }^{34}$ Samuel J. Wikolaski, Tafsiran Alkitab Masa Kini Volume Tiga, (Jakarta: BPK Gunung Mulia, 1981), 593
} 
didasarkan pada kesadaran akan hubungan yang benar dengan Allah. ${ }^{35}$ Dalam bahasa Yunani sehari-hari pada masa gereja mula-mula, kata ini dipakai dengan kegunaan yang menarik. Kata itu digunakan untuk ketentraman yang dinikmati oleh suatu Negara karena berlakunya keadilan dan kemakmuran di bawah pemerintahan kepala Negara yang bijaksana. Kata ini juga digunakan untuk tata tertib yang berlaku dan dan terpelihara dalam suatu kota dan desa. Di setiap desa biasanya ada seorang pemimpin yang bertugas menguasai eirene di desa itu, yaitu yang lazim disebut pemelihara damai sejahtera rakyat. ${ }^{36}$ Dalam Perjanjian Barueirene biasanya diartikan sama dengan kata shalom, yang tidak hanya berarti bebas dari kesulitan, tetapi juga menyangkut setiap hal yang membawa kebaikan tertinggi bagi manusia. Dalam teks ini, eirenen berarti ketenangan hati yang semata-mata bersumber pada kesadaran bahwa seluruh kehidupan orang percaya ada di tangan Allah. ${ }^{37}$ Damai sejahtera, suasana aman, tentram, dan damai sejahtera dalam kehidupan sebenarnyadicari oleh manusia sepanjang zaman dimanapun juga. Damai sejahtera sejati tidak bisa diukur oleh materi atau hal apa saja. Damai sejati adalah anugerah Tuhan (Yohanes 14:27). Damai sejahtera ini lahir dari keyakinan akan kesempurnaan pemeliharaan Tuhan dalam setiap detail kehidupan orang percaya.

Menurut Kamus Besar Bahasa Indonesia(KBBI), sabar berarti tahan menghadapi cobaan (tidak lekas marah, tidak lekas putus asa, tidak lekas patah hati), tabah, tenang, tidak terburu-buru, tidak terburu nafsu. ${ }^{38}$ Kesabaran adalah sikap seseorang terhadap orang lain dan mencakup ketidaksediaan untuk membalas kejahatan dengan kejahatan. Kesabaran berbicara tentang ketabahan, kesetiaan jiwa meskipun karena dihasut. Hal tersebut mengandung ide kesabaran dan kekuatan kesabaran walaupun menerima perlakuan yang

\footnotetext{
${ }^{35}$ Kenneth S. Wuest, Wuest's Word Studies From The Greek New Testament..., 160

${ }^{36}$ William Barclay, Pemahaman Alkitab Setiap Hari..., 80

${ }^{37}$ Ibid.,..., 80

${ }^{38}$ Lukman Ali, Kamus Besar Bahasa Indonesia, (Jakarta: Departemen Pendidikan dan Kebudayaan, 1991), 763
} 
kasar, dengan kemarahan atau pikiran untuk balas dendam. ${ }^{39}$ Menurut William Barclay, kesabaran (makrothumia) adalah semacam sikap tekun dan sabar yang membawa kemenangan, kesabaran terhadap manusia. Chrisostomus berkata bahwa makrothumia adalah pahala bagi orang yang tidak cepat, bahkan tidak bisa marah, orang yang mampu menahan diri dan tidak membalas dendam. ${ }^{40}$ Kesabaran adalah sifat seseorang yang mampu menempatkan diri dengan orang lain, walaupun orang lain berat untuk mencobanya. Pentingnya kesabaran dibuktikan dengan sifat yang digunakan oleh Allah, bahwa Allah adalah panjang sabar.

King James Version menerjemahkannya kemurahan dengan kindness,good, gentlesnes.Dalam bahasa Yunani dituliskan khrestotes, berasal dari kata sifat khrestos artinya yang mudah, baik, berguna, menguntungkan. ${ }^{41}$ Sedangkan William Barclay menuliskan bahwa khrestotes berarti menolong. Contohnya ketika Yesus diminyaki kaki-Nya oleh perempuan berdosa itu. ${ }^{42}$ Karakter ini berarti kebaikan yang diepnuhi dengan kemurahan hati. Khrestotes membuat orang percaya bisa bersikap baik dan murah hati terhadap sesamanya yang membutuhkan, bahkan termasuk kepada mereka yang tidak menyenangkan. Kata khrestotes secara konseptual bermakna keramahtamahan, kebaikan hati, penuh daya guna. Kata ini sering digunakan berpadanan dengan kata lain untuk menegaskan maknanya. Dalam Perjanjian Lama, kemurahan merupakan salah satu sikap Allah terhadap manusia, penuh kasih sayang, dimana Allah dalam kedaulatan-Nya suka berbuat baik dan memberikan apa yang baik kepada manusia.

Kebaikan berasal dari kata sifat agathos artinya yang baik, bagus, berguna. Kebaikan adalah ketulusan jiwa yang membenci kejahatan, motif

\footnotetext{
${ }^{39}$ Kenneth S. Wuest, Wuest's Word Studies From The Greek New Testament..., 160

${ }^{40}$ William Barclay, Pemahaman Alkitab Setiap Hari..., 81

${ }^{41}$ Ibid.,

${ }^{42}$ William Barclay, Pemahaman Alkitab Setiap Hari..., 81
} 
dan perilaku baik. ${ }^{43}$ William Barclay menuliskan kebaikan adalah kebajikan yang tersedia dalam segala perkara. Agathosune mengandung unsur marah dan disiplin. Contohnya ketika Yesus mengadakan pembersihan di bait Allah serta mengusir mereka yang menjadikan tempat itu sebagai tempat perdagangan. ${ }^{44}$ Agathosune berarti kebaikan yang mengandung unsur memperbaiki dan mendisiplin agar orang lain lebih baik. Kata benda agathosune secara konseptual bermakna kebaikan hati dan tindakan, lahir dan batin. Kebaikan mencerminkan budi pekerti yang ideal, yang diiringi dengan kebenaran dan kasih.

Kesetiaan berasal dari kata pistisartinya meyakinkan, mempercayai, mentaati, menaruh keyakinan, percaya, yakin. ${ }^{45}$ Menurut William Barclay, kesetiaan dapat diartikan layak untuk dipercaya. Kata ini menunjuk pada ciri khas orang yang dapat diandalkan. ${ }^{46}$ Dalam teks ini, pistis diterjemahkan kesetiaan yaitu kejujuran dan integritas dalam tindakan orang percaya, komitmen dan tanggung jawab. Karakter ini merupakan implikasi dari kesadaran bahwa orang percaya memahami dan memiliki Allah Yang Maha Tahu, Maha Melihat.

Kelemahlembutan diterjemahkan dari kata Yunani praotes berasal dari kata sifat praos, lemah, ringan, perlahan, lembut. Secara konseptual praotes atau kelemahlembutan adalah lembut plus sabar dalam sikap dan pembicaraan, tidak mudah mengeluarkan perkataan yang kasar apalagi marah. Aristoteles, seorang filsuf Yunani menulis bahwa praotes terletak antara orgilotes (marah kelewatan dan tidak terkontrol) dengan aorgisia (ketidakmarahan yang berlebihan). ${ }^{47}$ Menurut William Barclay, kata kelemahlembutan memiliki tiga arti. Pertama, patuh pada kehendak Allah. Kedua, mau diajari dalam arti tidak sombong untuk menerima pengajaran.

\footnotetext{
${ }^{43}$ Ibid.,

${ }^{44}$ William Barclay, Pemahaman Alkitab Setiap Hari..., 82

${ }^{45}$ Ibid.,

${ }^{46}$ William Barclay, Pemahaman Alkitab Setiap Hari..., 82

${ }^{47}$ Ibid.,
} 
Ketiga, lemah lembut, pengendalian diri. ${ }^{48}$ Kelemahlembutan bukanlah sebuah kelemahan tetapi sebuah kekuatan.Karena seseorang menyerahkan masalahnya di bawah kontrol Allah, sehingga dimampukan untuk tetap bersikap lembut dan akan mendapatkan kemenangan. ${ }^{49}$

Penguasaan diri berasal dari kata egkrates artinya dapat menguasai diri. Penguasaan diri adalah karakter yang diberikan melalui kemenangan melawan daging dan yang mana disebabkan oleh kesucian, kemurnian, antara pikiran dan perbuatan. Penguasaan diri adalah kualitas yang besar yang datang kepada seseorang ketika Yesus Kristus tinggal di dalam hatinya, di mana sifat tersebut membuatnya mampu untuk hidup dan berjalan di dunia, dan sambil memelihara pakaiannya dari noda dunia. ${ }^{50}$ Penguasaan diri juga menunjukkan pembatasan diri. Dalam perikop ini berhubungan khususnya kepada pembatasan keinginan-keinginan daging, walaupun persoalan yang dihadapi mungkin adalah kurangnya pengekangan diri dalam setiap perangai. $^{51}$

Keempat, hidup yang melayani yaitu sesuai dengan karunia Roh Kudus. Dalam beberapa suratnya, rasul Paulus memberikan pemahaman kepada jemaat tentang karunia-karunia Roh Kudus. Rasul Paulus menegaskan bahwa apabila Allah memberikan karunia roh, maka karunia roh itu berfungsi untuk kepentingan bersama (sesama tubuh Kristus). Setiap anggota Gereja memiliki karunia yang bebeda-beda dankegunaannya masing-masing. Akan tetapi tujuan utamanya adalah pembangunan jemaat (Roma 12:2-5, 1 Korintus 12: 16, 1 Korintus 12:14). ${ }^{52}$ Lebih jauh, rasul Paulus menyatakan bahwa karunia dengan pelayanan jemaat adalah sebuah bagian yang utuh dan tidak bisa dipisahkan. Jemaat yang memiliki karunia namun tidak menggunakan karunia

\footnotetext{
${ }^{48}$ William Barclay, Pemahaman Alkitab Setiap Hari..., 82

${ }^{49}$ Warren W. Wiersbe, Be Free, An Expositions..., 135

${ }^{50}$ James Montgomery Boice, The Expositors Bble Commentary, (Grand Rapids, Michigan: Zondervan Publishing House, 1995), 499

${ }^{51}$ Samuel J. Wikolaski, Tafsiran Alkitab Masa Kini Volume Tiga, (Jakarta: BPK Gunung Mulia, 1981), 593

${ }^{52}$ Donald Guthrie, Teologi Perjanjian Baru, (Jakarta: BPK Gunung Mulia,1995), 201.
} 
tersebut untuk melayani telah menyangkal hakikat dari tujuan pemberian karunia rohani tersebut. Karena dalam pemahaman rasul Paulus setiap jemaat adalah komunitas karismatik. ${ }^{53}$ Ada dua kata Yunani yang digunakan untuk menjabarkan karunia roh. Pertama, kata Pneumatikos, artinya "hal-hal rohani" atau "sesuatu yang dikaitkan dengan Roh Kudus". ${ }^{54}$ Dalam 1 Korintus 12-14 kata pneumatikos ditemukan tiga kali. Pada 1 Korintus 14: 37 artinya jelas, yakni orang rohani. Dalam (TB) terdapat terjemahan 'karuniakarunia Roh' (1 Kor. 12:1; 14:1) sedangkan dalam (BIS) diterjemahkan 'karunia-karunia yang diberikan Roh Allah'. Tetapi pada umumnya kata "pneumatikos" diartikan dengan 'pemberian-pemberian rohani' atau lebih tepat diterjemahkan, yaitu karunia-karunia yang dianggap bersifat rohani. ${ }^{55}$ Kedua, kata lain yang digunakan untuk mengidentifikasi karunia roh adalah "Charisma". Dalam Perjanjian Baru, istilah charisma muncul 18 kali, yaitu 17 kali terdapat dalam surat-surat Paulus dan 1 kali dalam 1 Petrus. 4:10. ${ }^{56}$ Itu berarti seluruh penggunaan istilah charisma dalam Perjanjian Baru adalah khas Paulus. Kata charisma merupakan kata turunan dari kata charis, artinya anugerah (juga diterjemahkan kasih karuniaatau rahmat) dan kata kerja charizomai, artinyamemberi. ${ }^{57}$ Secara umum charisma dapat diartikan sebagai pemberian atau tanda anugerah Allah untuk kepentingan umat-Nya. Hal itu bukan perkembangan kemampuan secara alamiah melainkan suatu pemberian Allah yang dilimpahkan bagi orang percaya (1 Korintus 2:4) ${ }^{58}$ Charisma berasal dari anugerah (charis) Allah, dan karena kasih-Nya diberi tanpa syarat kepada manusia. Dengan pemakaian istilah charisma, Paulus menekankan bahwa karunia bukan sesuatu untuk menambah gengsi

\footnotetext{
${ }^{53}$ Siegfried Schatzmann, S. A Pauline Theology of Charismata, (Massachusetts: Hendrickson Publisher, 1989), 1-2.

${ }^{54}$ Paul Enns, The Moody Handbook Of Theology, (Malang: SAAT, 2012), 332

${ }^{55}$ David L. Baker, Roh dan Kerohanian Dalam Jemaat, (Jakarta: BPK Gunung Mulia, 1993), 34

${ }_{56}^{56}$ J. Koenig, God's Gifts for God's People, (Philadelphia: Westminster Press, 1978), 9

${ }^{57}$ Ibid..., 33

${ }^{58}$ John R. W. Stott, Babtisan dan Kepenuhan, (Jakarta: Yayasan Komunikasi Bina Kasih/OMF, 1991), 100
} 
seseorang sehingga dia dipandang sebagai orang rohani, melainkan suatu pemberian karena anugerah Allah dan untuk kepentingan umat-Nya. Jadi, karunia roh adalah kemampuan khusus yang diberikan kepada orang-orang percaya oleh Roh Kudus untuk memuliakan Kristus dan membangun gerejaNya. Karunia roh tidak diperoleh karena pekerjaan yang baik, punya talenta atau kemampuan-kemampuan alamiah. Namun karunia roh merupakan pemberian dari Tuhan, oleh sebab itu tidak mungkin seseorang mendapatkannya melalui kerja keras atau memperoleh karena layak atau mempelajarinya dari buku-buku.

\section{KESIMPULAN}

Filsafat postmodern memberikan penawaran cukup "instant" dan "menggoda" umat manusia. Konsep-konsep makna dibalik filosofinya, sangat menggiurkan sehingga bisa menghancurkan, jikalau tidak diantisipasi dengan baik. Namun bisa juga akan menjadi baik, jikalau umat manusia memiliki kekuatan mengendalikannya. Filsafat postmodern ini ibarat "pisau tajam" di tangan kita, bisa untuk "mematikan" dan bisa juga digunakan untuk mempercepat pekerjaan. Satu-satunya cara membentengi diri pada gerakan arus zaman dan filsafat postmodern (hal-hal negatifnya) adalah dengan menghidupi nilai-nilai spiritual Kristiani yang tertulis di dalam Alkitab firman Allah dan telah dipraktikkan oleh Tuhan Yesus Kristus, seperti yang tertulis di dalam Alkitab firman Allah.

Pada hakikatnya Spiritualitas Kristiani bukan berorientasi kepada teoriteorinya, tetapi pada praktinya. Nilai-nilai Spiritualitas Kristiani hanya bisa bermakna jikalau orang Kristen mampu melakukannya dalam konteks kehidupan setiap hari. Orang percaya di era postmodern, bukan hanya menunjukkan status sebagai seorang yang memiliki agama. Melainkan mendemonstrasikan dan memproklamirkan nilai-nilai kebenaran itu bagi dunia ini, baik itu sifat ilahi yang tertanam di dalam hati, karakter yang telah 
diubahkan, keteladan hidup maupun kehidupan doa dan persekutuan dengan Allah. Orang percaya haruslah menjaga kekudusan hidup di tengah kemajuan zaman yang terus menerus berubah. Tentu hal ini haruslah secara konsisten dan terus-menerus dilakukan, sebab merupakan aktifitas orang percaya dalam rangka penyembahan kepada Allah yang Kudus. Soli Deo Gloria 


\section{DAFTAR PUSTAKA}

Ali, Lukman.,

1991 Kamus Besar Bahasa Indonesia, Jakarta: Departemen Pendidikan dan Kebudayaan.

Barclay, William.,

2000 Pemahaman Alkitab Setiap Hari Kitab Galatia dan

Efesus, Jakarta: BPK Gunung Mulia.

Bambang Sugiharto, I.,

2008 Postmodernisme: Tantangan Bagi Filsafat, Yogyakarta : Penerbit Kanisius.

Barnhart, C \& Jess Stein.,

1964 The American College Dictionary, New York : Random House and Toronto.

Brake, Andrew.,

2013 Spiritual Formations, Bandung : Kalam Hidup.

B. Lumintang, Ramly.,

2010 Bahaya Postmodernisme \& Peranan Kredo Reformed, Batu : Departemen Multimedia IPO.

B. Simpson, A.,

Carter, Les.,

Mengikuti Pimpinan Roh, Bandung: Kalam Kudus

1995 Reflecting the Character of Christ, Nasville : Thomas Nelson Publishers.

Ellingworth, Paul \& Howard Hatton.,

2010 A Translator's Handbook on Paul's First Letter to the

Corinthians. Jakarta : Lembaga Alkitab Indonesia.

E McGrath, Alister.,

2003 Christian Spirituality, UK : Blackweell Publishing.

Enns, Paul.,

2012 The Moody Handbook Of Theology, Malang: SAAT.

Gaut, Willy.,

2010 Filsafat Postmodernisme : Jean Francois Lyotard, Maumere : Penerbit Ledalero.

Guthrie, Donald.,

1995 Teologi Perjanjian Baru, Jakarta: BPK Gunung L J. Hendriksen, William.,

1990 New Testament Commentary Galatians and Ephesians,

Michigan: Baker Book House.

Wikolaski, Samuel.,

1981 Tafsiran Alkitab Masa Kini Volume Tiga, Jakarta: BPK Gunung Mulia

Packer, J., 
2004 God's Plans For You, Surabaya : Momentum

Koenig, J.,

1978 God's Gifts for God's People, Philadelphia: Westminster Press.

K. Simpson, E \& F. F Bruce (ed),

1979 The New International Commentary On The New

Testament: The Epistles to The Ephesians and $\mathrm{L}$.

L. Baker, David.,

1993 Roh dan Kerohanian Dalam Jemaat, Jakarta:

BPK Gunung Mulia.

M. Moeliono, Anton.,

1990 Kamus Besar Bahasa Indonesia, Jakarta : Balai Pustaka. Montgomery Boice, James.,

1995 The Expositors Bible Commentary, Grand Rapids, Michigan: Zondervan Publishing House

M. Horton, Stanley.,

Oknum Roh Kudus, Malang: Gandm Mas.Prent, K.,

1969 Kamus Latin-Indonesia, Yogyakarta : Kanisius

R. W. Stott, John.,

1991 Baptisan dan Kepenuhan, Jakarta: Yayasan Komunikasi Bina Kasih/OMF.

Schatzmann S, Siegfried.,

1989 A Pauline Theology of Charismata, Massachusetts:

Hendrickson Publisher.

Susanto, Hasan.,

$2010 \quad$ Perjanjian Baru Interlinier Yunani Indonesia \&

Korkondansi Perjanjian Baru (PBIK) Jilid I, Jakarta:

Lembaga Alkitab Indonesia

S. Dockery, David.,

1995 The Challenge of Postmodernism an Evangelical Engagement, Grand Rapids : Baker Books

S. Wuest, Kenneth.,

1989 Wuest's Word Studies From The Greek New Testament For English Reader Volume One, Grand Rapids, Michigan: Wm. B. Eerdmans.

V. G. Tasker, R (ed).,

1982

The Epistles Of Paul to The Colossians \& Philemon,

Grand Rapids, Michigan: Wm. B. Eedmans publishing Company

W. Wiersbe, Warren.,

1981 Be Free, An Expositions Study Of Galatians, Wheaton, Illionis: Victor Books 